Journal of Education and Vocational Research

Vol. 3, No. 7, pp. 234-241, July 2012 (ISSN 2221-2590)

\title{
Technological Factors Affecting Knowledge Sharing among Academic Staff in Selected Malaysian Higher Educational Institutions and the Effect on Performance
}

\author{
Norizah Supar \\ International Islamic University, Malaysia \\ norizahs@iium.edu.my
}

\begin{abstract}
The objective of this study is to expand our understanding of the factors that affect knowledge sharing among academic staff in Malaysian higher academic institutions. Although previous research has identified several factors that affect knowledge sharing, further research needs to be carried out to ascertain factors that affect knowledge sharing, in particular among higher academic institutions in Malaysia. Its relevance to higher academic institutions is especially pertinent considering that being a center of learning, a higher level of knowledge sharing among the teaching staff could bring about an increased level of productivity or performance and satisfaction in the workplace. The outcome of this study will enable further understanding on knowledge sharing behavior of academic staff and may therefore contribute towards successful implementation of knowledge sharing as part of organizational knowledge management initiatives. Based on non-random, criterion, purposive sampling, three higher academic institutions from the Klang Valley area were selected to be included in the study. Findings from 194 respondents indicated that the technological factors of distributed model and presence of IT for knowledge sharing are positively related to knowledge sharing and that knowledge sharing is positively related to performance.
\end{abstract}

Keywords: Knowledge Sharing, Technology, Collaborative Technology, Distributed/Networked Model, Performance

\section{Introduction}

The effective management of knowledge is crucial for ensuring competitive advantage (Davenport \& Prusak, 1998; Drucker, 1993; Hansen, Nohria \& Tierney, 1999). One major aspect in the effective management of this resource deals with the sharing of knowledge between individuals and departments in the organization (O'Dell \& Grayson, 1998). Through sharing, new knowledge is created, and this, in turn, acts as a catalyst for innovation (Maponya, 2005). A vital consideration in knowledge management is to systematically foster knowledge sharing among organization members (Chua, 2003; Martin, 2000). Despite the growing evidence on the advantage of knowledge sharing for organizational and individual growth, there is a strong tendency among organizational members to hoard knowledge as it is often perceived that knowledge is 'power' as well as a source of personal advancement (Gurteen, 1999; Wah, 1999). When knowledge is viewed as a weapon to be employed for personal advantage and competition, it might hamper the whole process of knowledge sharing.

\section{Literature Review}

Technology and Knowledge Sharing: When considering technology in relation to knowledge sharing, there are views that strongly support the use of technology and views that are skeptical about the role of technology in knowledge sharing. The third view regards technology as playing a supporting role in relation to other factors such as culture and social networks. There are strong indications that technology is being viewed as playing an important as well as a supporting role. Under technology, four factors are found to be relevant in relation to knowledge sharing. The four factors are IT infrastructure, IT for knowledge sharing (collaborative technology), codification and expert vs. distributed model (Beckman, 1999; Connelly \& Kelloway, 2001; Davenport \& Prusak, 2000; Dixon, 1999; 2000; Gottschalk, 2002; Jones, 2001; Nonaka \& Takeuchi, 1995; Pan \& Scarbrough, 1998). The relationship between these factors and knowledge sharing are explained below. 
IT Infrastructure: IT infrastructure needs to be available in order to facilitate the sharing of knowledge. To be applied, knowledge and expertise must be readily accessible, understandable, and retrievable (Beckman, 1999). According to Gottschalk (2002), a number of IT infrastructures are required in an IT-supported KM. Technical infrastructure needs to be in place, including a network, personal computers, databases and software; application architecture has to be in place, linking the various software applications; and information architecture is required, enabling the flow of information between various systems. The importance of IT infrastructure is supported by results obtained from past research (Wood, 2005) that IT support produce a significant positive influence on knowledge orientation. Research by Kim \& Lee (2006) also found that employee usage of IT applications significantly affect employee knowledge-sharing capabilities. A study by Soo, (2006) showed that besides being an important enabler, technology could be intrinsically motivating if it is easy to use.

IT for Knowledge Sharing (Collaborative Technology): IT for knowledge sharing in terms of collaborative technology (Jones, 2001) refers to technologies or systems that allow employees to contribute their expertise in such a way that it can be easily accessed by other employees. Other terms have been used to refer to such technologies, such as communications network (Gamble \& Blackwell, 2001) and knowledge sharing technologies (Connelly \& Kelloway, 2001).

Codification: Codification is the conversion from tacit to codified knowledge (Nonaka \& Takeuchi, 1995). According to Davenport \& Prusak (2000), codifying knowledge is an essential step in leveraging its value in the organization. Codification gives permanence to knowledge that may otherwise exist only inside an individual's mind. It represents or embeds knowledge in forms that can be shared, stored, combined, and manipulated in a variety of ways. The aim of codification is, therefore, to put organizational knowledge into a form that makes it accessible to those who need it. There is difficulty of converting tacit knowledge into explicit knowledge. However, codification is an important process, as the tacit knowledge that may be codified or turned into explicit knowledge can be made available in computer databases to facilitate sharing.

Expert (Hierarchical) Model vs. Distributed (Networked) Model: People frequently seek information and insights outside their immediate workgroup or team (McDermott \& O'Dell, 2001). Dixon (2000) stated that there is a shift from thinking of experts as the primary source of knowledge to thinking that everyone engaged in work tasks has knowledge someone else could use to advantage - from expert to distribute. There are two models on the flow of knowledge (Dixon, 2000). The first is the Expert (Hierarchical) Model. This model states that the flow of knowledge is from a few designated experts to those who were less expert as shown in Figure 1 (Dixon, 2000).

Figure 1: The Expert Model- knowledge is transferred from a few designated experts

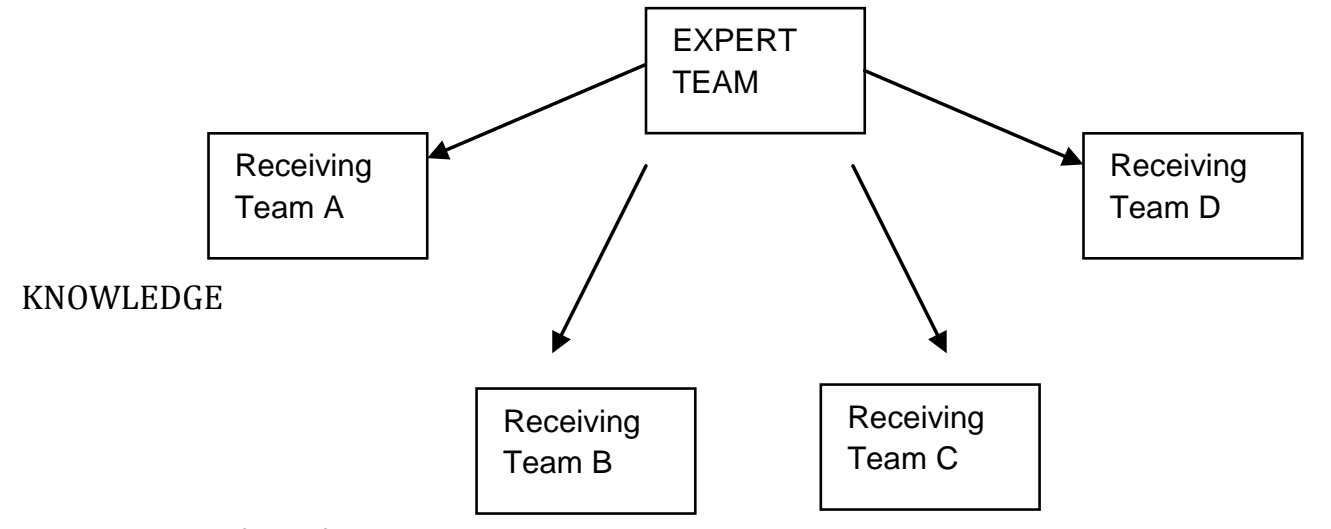

Source: Dixon (2000)

The second is the Distributed Model. According to Dixon (2000), there is a shift from the notion that knowledge is found only in a select group of experts or "best" practitioners and toward the idea that useful knowledge is distributed throughout the whole of an organization. This model views knowledge as widely 
distributed across organizational members rather than residing in a small number of experts. The distributed view of organizational knowledge is shown in Figure 2 (Dixon, 2000) as follows:

Figure 2: The Distributed Model - knowledge is transferred among teams

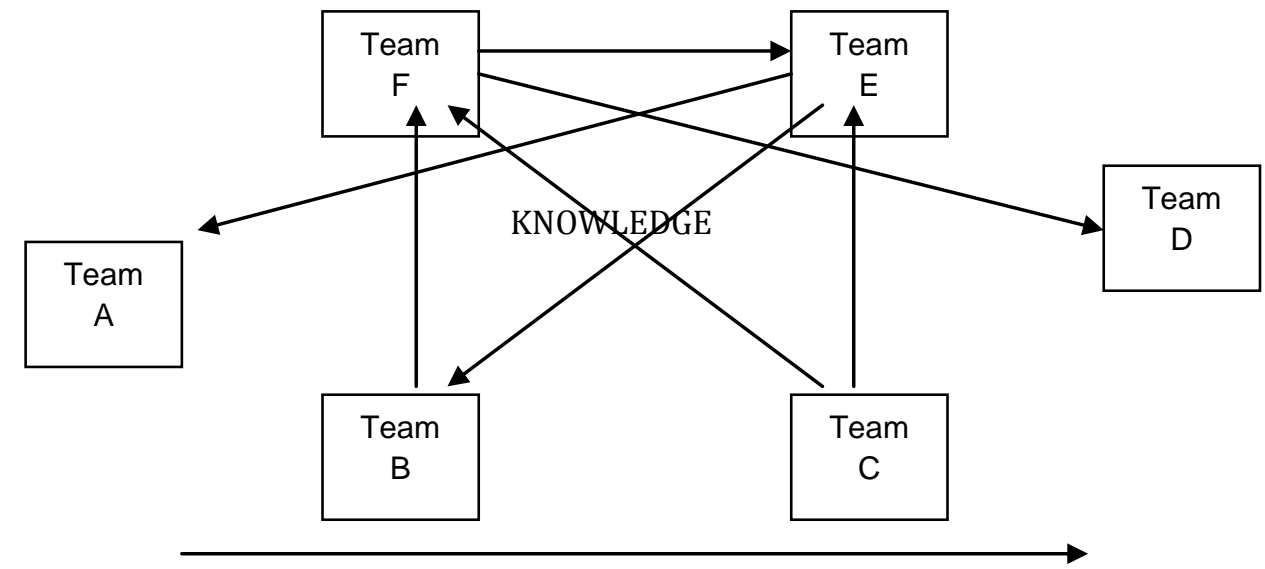

Source: Dixon (2000)

The expert model vs. distributed model has important implications in how the IT or knowledge system is designed. Depending on which model appeal more to users, this will have an effect on whether or not knowledge sharing is encouraged. Expert vs. distributed model is therefore considered as an important factor under technology as the way the system is designed and set up, i.e. whether it is expert-based (hierarchical) or distributed (networked), will determine the directions of knowledge flow and therefore affect knowledge sharing among the users.

Research Questions: The research questions that this study seeks to answer are as follows:

- What are the significant technological factors affecting knowledge sharing?

- What is the relationship between knowledge sharing and performance?

Propositions: Technological Factors and Knowledge Sharing Considering the various factors under technology namely IT infrastructure, IT for KS, codification and expert vs. distributed model, the model relating technological factors to knowledge sharing is therefore as follows:

- IT infrastructure

- IT for KS Knowledge

- Codification Sharing

- Expert vs. distributed model

The propositions are as follows:

Proposition 1: IT infrastructure is positively related to knowledge sharing

Proposition 2: IT for knowledge sharing (collaborative technology) is positively related to knowledge sharing Proposition 3: Codification is positively related to knowledge sharing

Proposition 4: A distributed (networked) model is positively related to knowledge

Knowledge Sharing and Performance: Knowledge initiatives in firms (O'Dell \& Grayson, 1998) and research (Kogut \& Zander, 1992; Riesenberger, 1998) have shown that there is a positive relationship between knowledge sharing and performance. Beckman (1997) also argues that knowledge sharing is one of the most important factors affecting performance (Kim \& Lee, 2006). The case study by Jones (2001) demonstrated qualitatively that sharing information with BSCW (basic support for cooperative work) saved significant amounts of time in different processes, improved decision-making, quality and problem solving. It can therefore be concluded that there is a positive relationship between knowledge sharing and performance. The model is therefore as follows:

Knowledge Sharing $\longrightarrow \quad$ Performance

The proposition is as follows: 
Proposition 5: Knowledge sharing is positively related to performance

\section{Methodology}

The data for this study was collected as part of a research on factors contributing to knowledge sharing. A questionnaire was constructed to assess dimensions on technology, knowledge sharing and performance. The dimensions on technology are based on a review of earlier work done by other researchers (Knowledge Centric Organization (KCO) Assessment (2001).

\section{Research Design}

Population and Sample: The population for this study is composed of the academic staff from public and private institutions located in the Klang Valley area of Malaysia. In this study, due to time and geographical constraints, three higher educational institutions were selected based on purposive sampling. The unit of analysis in this study is the academic staff in the higher educational institutions. 194 usable responses were received.

Methods of Analysis: For methods of analysis, the researcher used Principle Component Analysis (PCA), Confirmatory Factor Analysis (CFA) and Structural Equation Modeling (SEM). The PCA was used to categorize the items into latent variables and to verify the reliability and dimensionality of the items. Confirmatory Factor Analysis (CFA) was then employed to confirm the results of PCA and to further explore the uniqueness of each variable per se. SEM was employed to test the propositions, answer the research questions and further test the reliability of the items as well as the model.

Sampling Design: In selecting the sample for this study, a non-random, criterion, purposive sampling (Gay \& Airasian, 2000) approach was used. The criteria for selection of the organizations are as follows:

- One organization selected should be from among the public universities.

- One organization selected should be from among the private universities.

- The third organization selected has another criterion not available in the other two universities. It is international in nature and has a comparatively higher number of non-Malaysian academic staff.

Although the results of this study may not be generalized to the population as only one institution has been selected to represent each category, the results of this study can still be made to describe the nature of knowledge sharing at these institutions as they share a number of characteristics. For example, all public universities in Malaysia implement the same remuneration scheme as well as having similar goals and aspirations. Private universities are geared towards being profit-oriented.

Perceptual Measure of Performance: Considering that there were limitations of non-standardization of data obtained from the three organizations in terms of actual performance of the academic staff on matters related to teaching, research, publication and consultancy, it was decided to obtain a perceptual measure of performance rather than the actual data on performance as perceptual measure may also be regarded as a reliable measure of performance (Jones, 2001).

\section{Results}

Relationship between Technological Factors and Knowledge Sharing: Based on the findings of the study, the following propositions are supported:

- Proposition 2: IT for knowledge sharing is positively related to knowledge sharing

- Proposition 4: Distributed model is positively related to knowledge sharing

The following propositions are not supported:

- Proposition 1: IT infrastructure is positively related to knowledge sharing

- Proposition 3: Codification is positively related to knowledge sharing

Relationship between Knowledge Sharing and Performance: The proposition is as follows: 
- Proposition 5: Knowledge sharing is positively related to performance

Respondent Profile: Table 1 as follows shows the findings on respondent profile:

Table 1: Respondent Profile

\begin{tabular}{lccl}
\hline Demographic Variables & No. of Respondent & \% & Cumulative \% \\
\hline GENDER & 44 & 50.6 & 50.6 \\
Male & 43 & 49.4 & 100.0 \\
Female & 1 & & \\
JOB TITLE & 50 & 1.1 & 1.1 \\
Professor & 1 & 57.5 & 58.6 \\
Lecturer & 35 & 4.1 & 59.8 \\
Assistant Lecturer & & & 100.0 \\
Tutor & 15 & 17.2 & \\
ETHNIC GROUP & 58 & 66.7 & 17.2 \\
Malay & 13 & 14.9 & 93.9 \\
Chinese & 1 & 1.1 & 100.9 \\
Indian & & & \\
African & 15 & 17.2 & 17.2 \\
AGE (IN YEARS) & 63 & 72.4 & 89.7 \\
Less than 25 & 7 & 8.0 & 97.7 \\
25 to less than 35 & 1 & 1.1 & 98.9 \\
35 to less than 45 & 1 & 1.1 & 100.0 \\
45 to less than 55 & & \\
Above or equal to 55 & 33 & 37.9 & 37.9 \\
HIGHEST ACADEMIC QUALIFICATION & 52.9 & 90.8 \\
Bachelor's Degree & 46 & 9.2 & 100.0 \\
Masters Degree & 8 & & \\
PhD & &
\end{tabular}

Summary and Discussion of Research Findings: To examine the interdependent relationships among the variables, SEM analysis was carried out. The results showed the significant technological variables to be presence of IT for knowledge sharing and expert vs. distributed model. Table 2 as follows shows the results:

Table 2: Summary of Results of SEM

\begin{tabular}{|c|c|c|c|c|}
\hline No. & Propositions & Status & $\begin{array}{l}\text { Evidences/ } \\
\text { Type of Tests }\end{array}$ & Results \\
\hline 1. & $\begin{array}{l}\text { IT infrastructure is positively related to } \\
\text { knowledge sharing }\end{array}$ & NS & Path Analysis & $\mathrm{t}=-.93, \mathrm{p}<.05$ \\
\hline 2. & $\begin{array}{l}\text { IT for knowledge sharing is positively related } \\
\text { to knowledge sharing }\end{array}$ & S & Path Analysis & $\mathrm{t}=2.19^{*}, \quad \mathrm{p}<.05$ \\
\hline 3. & $\begin{array}{l}\text { Codification is positively related to } \\
\text { knowledge sharing }\end{array}$ & NS & Path Analysis & $\mathrm{t}=.13, \quad \mathrm{p}<.05$ \\
\hline 4. & $\begin{array}{l}\text { Expert vs. Distributed Model is positively } \\
\text { related to knowledge sharing }\end{array}$ & $S$ & Path Analysis & $\mathrm{t}=2.51^{*}, \quad \mathrm{p}<.05$ \\
\hline 5. & $\begin{array}{l}\text { Knowledge sharing is positively related to } \\
\text { performance }\end{array}$ & S & Path Analysis & $\mathrm{t}=4.81^{*}, \quad \mathrm{p}<0.05$ \\
\hline \multicolumn{5}{|c|}{$\begin{array}{l}\mathrm{S}=\text { Supported, NS }=\text { Not Supported } \\
\mathrm{t} \text {-value }>1.740 \text { or }<-1.740 \text { significant at } .05 \text { level }(1 \text {-tailed), } \mathrm{df}=17\end{array}$} \\
\hline
\end{tabular}


on knowledge sharing by Jones (2001) on the importance of expert vs. distributed model (Dixon, 2000). The results also indicated that two (2) factors were not significant in affecting knowledge sharing. They were IT infrastructure and codification. Although IT infrastructure is considered important, this factor in itself is not significant in affecting knowledge sharing. For codification, the result also indicated that it is not significant in affecting knowledge sharing. One reason may be that knowledge may be shared by other means, such as through face-to-face interaction (through personalization strategy), rather than the sharing of codified knowledge which is available in databases (through codification strategy).

Factors Found to be Significant in Affecting KS: The following will elaborate on the factors found to be significant in affecting KS.

IT for Knowledge Sharing (Collaborative Technology): The research by Gottschalk (2002) indicates that a number of IT infrastructures are required in an IT-supported KM. The results of this study support past research and the literature pertaining to IT infrastructure for the purpose of knowledge sharing. They show that IT infrastructure alone is inadequate and that it has to be supported with a facilitating KS mechanism or technology in order to affect and promote KS. This facilitating KS mechanism has been identified using various terms such as collaborative technology (Jones, 2001), communications network (Gamble \& Blackwell, 2001) and knowledge sharing technologies (Connelly \& Kelloway, 2001).

Expert (Hierarchical) Model vs. Distributed (Networked) Model: Dixon (2000) stated that there is a shift from thinking of experts as the primary source of knowledge to thinking that everyone engaged in work tasks has knowledge someone else could use to their advantage - from the expert to distributed models. The distributed model views knowledge as widely distributed across organizational members rather than residing in a small number of experts. It indicates that knowledge is located in a multitude of diverse people and places across the organization. The concept of how we think about knowledge, that is whether it is expert based or distributed, is important because it has an influence on how a knowledge system is designed. The results showed that the distributed model significantly affects knowledge sharing. The findings of this study support the view of Dixon (2000) regarding the distributed model as the preferred model rather than the expert model.

Effect of knowledge sharing on performance: Various authors have indicated that knowledge sharing could result in performance improvements. The case study by Jones (2001) demonstrated qualitatively that sharing information with BSCW (basic support for cooperative work) saved significant amounts of time in different processes, improved decision-making, quality and problem solving. Knowledge sharing will also lead to better quality of decisions if the knowledge that is being contributed is actually important for achieving the goal and if members have the desire and the ability to benefit from that knowledge (Srivastava, 2001). Wiig (1999) described the benefits of a knowledge management system as reducing costs due to benchmarking and sharing best practices between different groups inside and outside the organization, decreasing time-in-process, reducing rework and increasing customer satisfaction and quality by increasing people's knowledge and improvement of processes. The results of this study indicated that KS is significantly related to performance. In this case, KS leads to improved performance in terms of teaching and research as well as improving the efficiency and productivity of the respondents' work processes, their innovation and their ability to do their job. The result of the study is, therefore, in line with the previous research and literature pertaining to KS and performance (Jones, 2001; Srivastava, 2001; Wiig, 1999).

Recommended Model: Based on the results of the study, the recommended model of technological factors in relation to knowledge sharing is shown in Figure 3 as follows:

Overall Overview on the Results of this Study: As an overall overview, the results of this study showed that there are two factors, which are positively related to knowledge sharing. They are IT for KS (collaborative technology) and distributed (networked) model. KS is also significantly and positively related to performance in terms of teaching and research, improving the efficiency and productivity of the respondents' work processes, their innovation and their ability to do their job. 
Figure 3: The Recommended Model of KS (in terms of the significant technological variables affecting knowledge sharing)

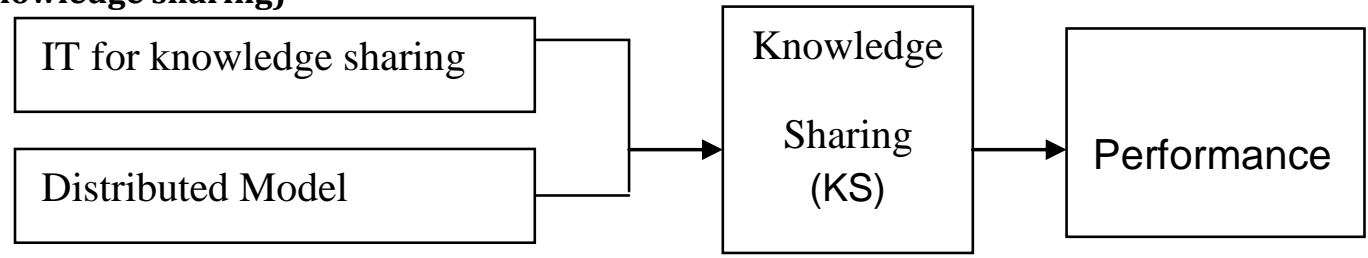

Discussion on Overall Overview: From the findings of this study and other related studies as stated above, the following observations and conclusions could therefore be made:

- based on the factors which have a positive relationship to knowledge sharing, there are some factors which agree with results obtained by previous other researches on knowledge sharing such as for IT for KS (collaborative technology) (Pan \& Scarbrough, 1998; Jones, 2001; Gamble \& Blackwell, 2001; Connelly \& Kelloway, 2001) and distributed (networked) model (Dixon, 2000).

- Knowledge sharing is also significantly and positively related to performance, as shown in previous studies (Jones, 2001; Chen, 2006).

Suggestions for Future Research: Future research could consider some of the following points to enable improvements to be made to the overall knowledge-sharing model:

- It would be more useful to include a larger number of higher academic institutions from all over the country from among the public-funded and private-funded organizations. This is to enable a higher generalizability of the results of the study to be obtained.

- Apart from the academic staff of higher institutions, the study on knowledge sharing could be carried out on staff from other types of institutions such as those in the manufacturing sector and service sector. Studies carried out in organizations other than academic institutions will enable further conclusions to be made regarding the level of knowledge sharing among the different types of organizations and will help in understanding the various factors that may affect KS.

- As regards the knowledge management strategy adopted with reference to codification, Hansen et al. (1999) found two very different knowledge management strategies in place. They are the codification strategy and the personalization strategy. The codification strategy is used in companies that sell relatively standardized products that fulfill common needs where knowledge is carefully codified and stored in databases and it can be accessed and used repeatedly by anyone in the organization. The personalization strategy is used in companies that provide highly customized solutions to unique problems where knowledge is shared mainly through person-to-person contacts and where the chief purpose of computers is to help people communicate.

In this study, the lack of codification problem is not significant in affecting KS. It is possible that the academic institutions in the study are using a personalization strategy. Further research could be carried out to confirm which approach the institutions are adopting i.e. whether a codification or a personalization strategy and to identify which strategy would be more suitable for the organizations under study.

\section{Conclusion}

The results of the study indicated that the technological factors affecting knowledge sharing are IT for knowledge sharing and distributed model. By integrating the technological factors affecting knowledge sharing, knowledge sharing and performance in one model and investigating the factors simultaneously enables a deeper understanding to be obtained regarding the technological factors affecting knowledge sharing, knowledge sharing as a mediating factor and the effect of knowledge sharing on performance. The results of the study underscore the significance of technological factors in affecting knowledge sharing.

\section{References}

Beckman, T. (1997). A Methodology for Knowledge Management. International Association of Science and Technology for Development (IASTED) AI and Soft Computing Conference. Banff, Canada. 
Beckman, T. J. (1999). The Current State of Knowledge Management. In J. Liebowitz (Ed.), Knowledge Management Handbook. (1.1-1.22). CRC Press.

Chen, L. Y. (2006). Effect of Knowledge Sharing to Organizational Marketing Effectiveness in Large Accounting Firms That Are Strategically Aligned. Journal of American Academy of Business, 9(1), 176-183.

Chua, A. (2003). Knowledge Sharing: A Game People Play. Aslib Proceedings, 55(3), 117-129.

Connelly, C. E. \& Kelloway, E. K. (2001). Predictors of Employees' Perceptions of Knowledge Sharing Cultures. Queen's Centre for Knowledge-Based Enterprises. http://www.business.queensu,ca/kbe. Accessed on 14 August 2004.

Davenport, T. H. \& Prusak, L. (1998). Working Knowledge: How Organizations Manage What They Know. Harvard Business School Press, Boston.

Davenport, T. H. \& Prusak, L. (2000). Working knowledge: How Organizations Manage What They Know. Boston: Harvard Business School Press.

Dixon, N. M. (1999). The Changing Face of Knowledge. The Learning Organization, 6(5), 212-216.

Dixon, N. M. (2000). Common Knowledge: How Companies Thrive by Sharing What They Know? Harvard Business School Press.

Drucker, P. (1993). The Post-Capitalist Society. Butterworth-Heineman, Oxford.

Gamble, P. R. \& Blackwell, J. (2001). Knowledge Management: A State of the Art Guide. Kogan Page.

Gay, L. R. \& Airasian, P. (2000). Educational Research: Competencies for Analysis and Application (6 ${ }^{\text {th }}$ ed.). NJ: Prentice Hall.

Gottschalk, P. (2002). Knowledge management in the professions: a study of IT support in law firms. In S. Barnes (Ed.), Knowledge management systems: Theory and practice. (82-94). Thomson Learning.

Gurteen, D. (1999). Creating a Knowledge Sharing Culture. Knowledge Management Magazine, 2(5).

Hansen, M. T., Nohria, N. \& Tierney, T. (1999). What is Your Strategy for Managing Knowledge? In Harvard Business Review on Organizational Learning (2001). (61-86). Harvard Business School Press.

Jones, N. B. (2001). The Diffusion of a Collaborative CSCW Technology to Facilitate Knowledge Sharing and Performance Improvement. Unpublished Ph.D Thesis, University of Missouri-Columbia.

Kim, S. \& Lee, H. (2006). The Impact of Organizational Context and Information Technology on Employee Knowledge-Sharing Capabilities. Public Administration Review, 66(3), 370-386.

Knowledge Centric Organization (KCO) Assessment (ver 5.2, Jan. 2001). http://www.fgipc.org/02_Federal_CIO_Council/Downloads/90\%20KCO\%20Survey.doc. Accessed on 7 April 2003.

Kogut, B. \& Zander, U. (1992). Knowledge of the Firm, Combinative Capabilities, and the Replication of Technology. Organization Science, 3(3), 383-397.

Maponya, P. M. (2005). Fostering the Culture of Knowledge Sharing in Higher Education. South African Journal of Higher Education, 19(5), 900-911.

Martin, B. (2000). Knowledge Management within the Context of Management: An Evolving Relationship. Singapore Management Review, 22(2), 17-36.

Mc Dermott, R. \& O'Dell, C. (2001). Overcoming Cultural Barriers to Sharing Knowledge, Journal of Knowledge Management, 5(1), 76-85.

Nonaka, I. \& Takeuchi, H. (1995). The Knowledge Creating Company. Oxford University Press, New York.

O’Dell, C. \& Grayson, C. J. (1998). If Only We Knew What We Know: Identification and Transfer of Internal Best Practices. California Management Review, 40(3), 154-174.

Pan, S. L. \& Scarbrough, H. (1998). A Socio-Technical View of Knowledge-Sharing at Buckman Laboratories. Journal of Knowledge Management, 2(1), 55-66.

Riesenberger, J. R. (1998). Executive Insights: Knowledge - the Source of Sustainable Competitive Advantage. Journal of International Marketing, 6(3), 94-107.

Soo, K. S. (2006). Why Workers Share or Do Not Share Knowledge: A Case Study. Unpublished Ph.D Thesis, Indiana University.

Srivastava, A. (2001). Antecedents and Effects of Knowledge Sharing in Teams: A Field Study. Unpublished Ph.D Thesis, University of Maryland, College Park.

Wah, L. (1999). Behind the Buzz. Management Review, 2, 16-19.

Wiig, K. M. (1999). Introducing Knowledge Management into the Enterprise. In Jay Liebowitz (Ed.), Knowledge Management Handbook. (7-19). Boca Raton, FL: CRC Press.

Wood, C. (2005). An Empirical Examination of Factors Influencing Work-Unit Knowledge Management Effectiveness in Organizations. Unpublished PhD. Thesis, the University of Texas at Arlington. 